\title{
Antibacterial Activity of White Pepper Oleoresin Mediated Silver Nanoparticles against Oral Pathogens
}

\author{
Rachel Preethi Paul1, Anitha Roy², Maajida Aafreen M. ${ }^{3}$, Rajeshkumar Shanmugam
}

\begin{abstract}
${ }^{1}$ Department of Pharmacology, Saveetha Dental College and Hospital, Saveetha Institute of Medical and Technical Sciences, Saveetha University, Chennai, Tamil Nadu, India. ${ }^{2}$ Department of Pharmacology, Saveetha Dental College and Hospital, Saveetha Institute of Medical and Technical Sciences, Saveetha University, Chennai, Tamil Nadu, India.

${ }^{3}$ Department of Pharmacology, Saveetha Dental College and Hospital, Saveetha Institute of Medical and Technical Sciences, Saveetha University, Chennai, Tamil Nadu, India. ${ }^{4}$ Department of Pharmacology, Saveetha Dental College and Hospital, Saveetha Institute of Medical and Technical Sciences, Saveetha University, Chennai , Tamil Nadu, India.
\end{abstract}

\section{ABSTRACT}

\section{BACKGROUND}

Plant mediated biological synthesis of silver nanoparticles is gaining importance due to its eco friendliness and simplicity. Different types of nanoparticles such as metal, metal oxide, metal sulphide and polymer nanoparticles are used in different types of applications in the fields of electronics, communications, electrical, mechanical, medical, dental etc. Aim of the present study was to evaluate the antibacterial activity of white pepper oleoresin mediated silver nanoparticles against oral pathogens.

\section{METHODS}

In the present investigation, white pepper mediated synthesis of silver nanoparticles was carried out by the addition of silver nitrate with prepared white pepper oleoresin solution. White pepper oleoresin mediated silver nanoparticles were initially confirmed by colour changes and confirmed by UV-Visible spectroscopy. Anti-bacterial activity of the synthesised silver nanoparticles was carried out using agar well diffusion method. Different concentrations of silver nanoparticles were tested against different oral pathogens such as Staphylococcus aureus, Streptococcus mutans and Pseudomonas sp.

\section{RESULTS}

The solution containing white pepper oleoresin and silver nitrate solution showed a brown colour confirming the formation silver nanoparticles and peak at $350 \mathrm{~nm}$ revealed the silver nanoparticles surface plasmon resonance. The white pepper oleoresin mediated silver nanoparticles showed good antibacterial activity against all tested microorganisms and the maximum activity was found with Pseudomonas spp. followed by Staphylococcus aureus, and Streptococcus mutans.

\section{CONCLUSIONS}

Green synthesis of silver nanoparticles using white pepper oleoresin was of low cost and was convenient to carry out. Hence, white pepper oleoresin mediated silver nanoparticles may be used for the control of oral pathogens.

\section{KEY WORDS}

White Pepper Oleoresin, Green Synthesis, Nanoparticles, Oral Pathogens, Silver Nanoparticles

\author{
Corresponding Author: \\ Dr. Anitha Roy, \\ Department of Pharmacology, \\ Saveetha Dental College, \\ Chennai, Tamil Nadu, India. \\ E-mail: anitharoy2015@gmail.com
}

DOI: $10.14260 /$ jemds/2020/519

How to Cite This Article:

Paul RP, Roy A, Aafreen MM, et al. Antibacterial activity of white pepper oleoresin mediated silver nanoparticles against oral pathogens. J Evolution Med Dent Sci. 2020;9(33):2352-2355, DOI: $10.14260 /$ jemds/2020/510

Submission 25-01-2020,

Peer Review 21-06-2020,

Acceptance 29-06-2020,

Published 17-08-2020.

Copyright (C) 2020 JEMDS. This is an open access article distributed under Creative Commons Attribution License [Attribution 4.0 International (CC BY 4.0)] 


\section{BACKGROUND}

Nanotechnology is expected to be the basis of many main technology innovations in the $21^{\text {st }}$ century. Research and development in this field is growing rapidly throughout the world. A major output of this activity is the development of new materials in the nanometer scale, particulate materials with at least one dimensions of less than 100 nanometres (nm). $(1,2,3)$ Nanotechnology occupies tremendous application in diverse fixed such as chemistry, cosmetics, catalyst, energy, plasmonic, onto-electronics and medicine. In the branch of nanotechnology, the synthesis of nanoparticles and their development play a significant role because of their applications. Size up to $100 \mathrm{~nm}$ is usually referred to as nanoparticles. In the recent years there, there are various noble metals such a silver $(\mathrm{Ag})$, lead $(\mathrm{Pb})$, platinum $(\mathrm{Pt})$ and gold $(\mathrm{Au}) .{ }^{(4)}$ Among the above four, silver nanoparticles play a significant role in the file of biological systems, living organisms and medicine.(5,6) Silver has long been recognised as having inhibitory effect towards many bacterial strains and micro-organisms commonly present in medicinal and industrial process.(7) The most widely used and known applications of silver and silver nanoparticles include topical ointments and creams containing silver to prevent infections of burns and wounds.(8) Many attempts have been made to use silver nanoparticles as an anti- cancer. The strong toxicity of silver against wide range of micro-organisms is well known and silver nanoparticles have been recently shown to have promising anti-microbial material.(9) Sondi et al studied the antimicrobial activity of silver nanoparticles against Escherichia coli as a model of gram-negative bacteria.(7)

Piper nigrum family Piperacea has got application in food industry as well as in pharmaceutical industry. The medicinal properties of the pepper are due to the presence of an active compound called piperine with a molecular formula of $\mathrm{C}_{17} \mathrm{H}_{19} \mathrm{NO}_{3}$. The oleoresin extracts from white pepper is made up of $4.6-9 \%$ piperine, $6 \%$ pungent resin, $2.5 \%$ essential oil and starch. The oleoresin extracts from white pepper possesses a characteristic anti-inflammatory, antidepressant, anti-rheumatic and anti-diabetic properties.(10,11) In this present study, white pepper oleoresin was used for the synthesis of silver nanoparticles and was characterised by UV visible spectroscopy. The synthesised nanoparticles is used for the analysis of anti-bacterial activity against oral pathogens.

\section{METHODS}

\section{Preparation of White Pepper Oleoresin}

1 milli molar of silver nitrate solution was prepared initially by dissolving it in double distilled water. $90 \mathrm{ml}$ of this 1 milli molar solution was mixed with $10 \mathrm{ml}$ of white pepper oleoresin solution. The solution was kept in magnetic stirrer/ orbital shaker for the formation of nanoparticles. The colour change was observed visually and photographs were taken. (Graph 1).

\section{Preparation of Nanoparticles}

The nanoparticles solution was centrifuged using Lark refrigerator centrifuge. The solution was centrifuged at 8000 rpm for 10 minutes and the pellets were collected and washed with distilled water. The final purified pellets were collected and dried at 60 degree Celsius for 2 hours and stored in airtight Eppendorf tube.

\section{UV-Visible Spectroscopic Analysis of Silver Nanoparticles} The synthesised white pepper oleoresin mediated nanoparticles were confirmed by UV visible spectroscopy. 3 $\mathrm{ml}$ of the solution was taken in cuvette and scanned in double beam UV visible Spectrophotometer from $300 \mathrm{~nm}$ to $650 \mathrm{~nm}$. The results were recorded for the graphical analysis. (Graph 1)

\section{Antibacterial Activity of Nanoparticles against Oral Pathogens}

The agar well diffused method was used to determine the antibacterial activity of silver nanoparticles. Different concentration of silver nanoparticles was tested against Staphylococcus aureus, Streptococcus mutans and Pseudomonas. The fresh bacterial suspension was dispersed on the surface of Muller Hinton agar plates. Different concentration of nanoparticles $(20 \mu \mathrm{L}, 40 \mu \mathrm{L}$ and $60 \mu \mathrm{L})$ was incorporated into the wells and the plates were incubated at 37 degrees Celsius for 24 hours. The amoxicillin was used as positive control. Zone of inhibition was recorded in each plate.(12,13)

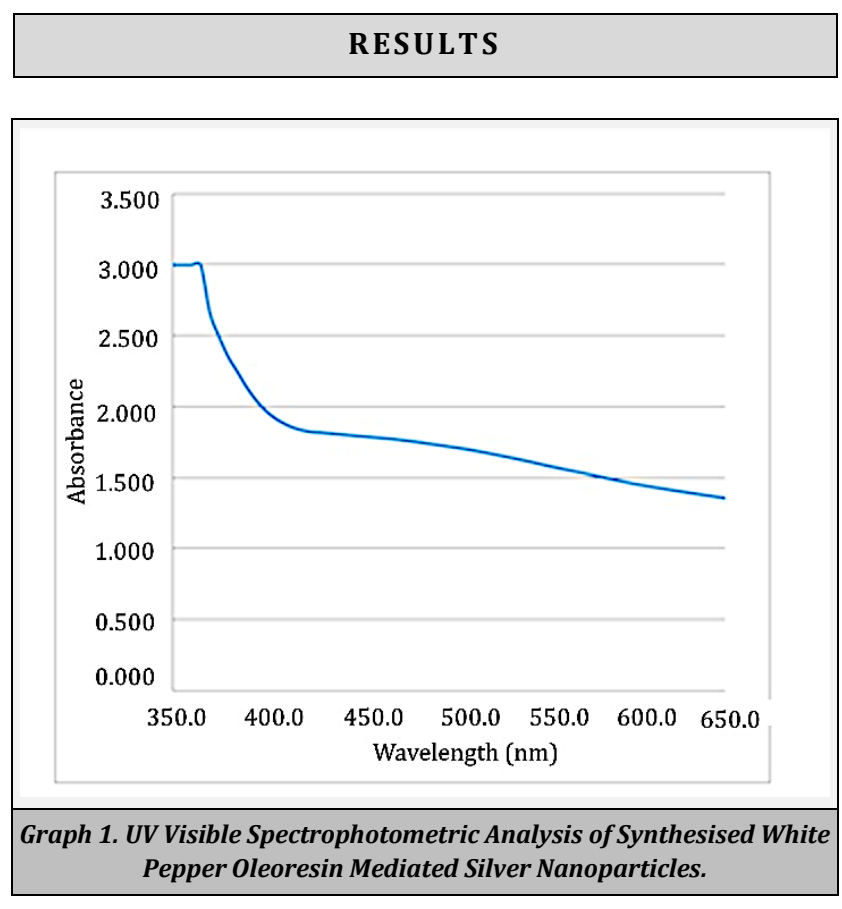




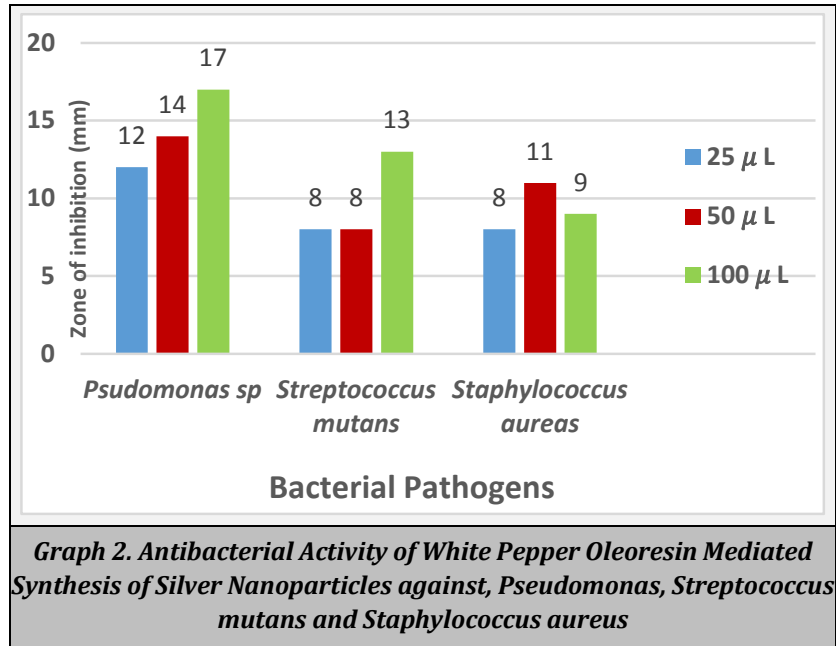

It was well known that silver nanoparticles exhibit yellowish discolouration colour in aqueous solutions due to excitation of surface plasmon vibrations in silver nanoparticles. The peak was observed at $350 \mathrm{~nm}$ showing the steady intensity as a function of reaction time. (Graph 1).(8)

The green synthesised silver nanoparticles were studied for its anti-microbial activity against oral pathogens bacteria by using agar well diffusion assay. The silver nanoparticles synthesised showed antibacterial activity against all the tested organisms especially against $\mathrm{S}$ mutans and $P$. aeruginosa. Maximum zone of inhibition was found to be with Pseudomonas aeruginosa.

\section{DISCUSSION}

\section{Anti-Bacterial Activity of Silver Nanoparticles}

Silver nanoparticles have the ability to attach to the bacterial cell and eventually penetrate into it thus causing structural changes in the cell membrane like the permeability of the cell membrane and death of the cell. The effect of silver nanoparticles were tested for the anti-microbial activity against oral pathogens namely Staphylococcus aureus, Streptococcus mutans and Pseudomonas aeruginosa. The extract obtained from white pepper oleoresin showed a zone of inhibition for the three pathogens. The zone of inhibition for Pseudomonas aeruginosa was comparatively larger than the other two showing increased effect of white pepper oleoresin mediated silver nanoparticles against the same. (Graph 2). $(9,14)$

The synthesis of nanoparticles is in the lime light of the modern technology. Biosynthesis of nanoparticles by plant extracts is currently under exploitation.(15-23) The development of biologically inspired experimental process for the synthesis of nanoparticles is evolved into an important branch of nanotechnology.(24-33) Silver nanoparticles find its use in many industries and the major applications include electronics, in optics and most importantly in the medical field as a bacterial and therapeutic agent. $(34,35)$

\section{CONCLUSIONS}

Biosynthesised silver nanoparticles using white pepper oleoresin have excellent anti-microbial property. The biological approach seems to be a very cost efficient alternative to the conventional physical and chemical methods of silver nanoparticles synthesis and would be suitable for developing a biological process for large scale products. This study demonstrated the possibility of using green synthesised silver nanoparticles. The study reveals that the silver nanoparticles from white pepper show a good activity on the oral pathogens. Hence this technology can be applied in therapeutics in the near future.

Financial or Other Competing Interests: None.

\section{REFERENCES}

[1] Santhoshkumar J, Kumar SV, Rajeshkumar S. Phytoassisted synthesis, characterisation and applications of gold nanoparticles - a review. Biochem Biophys Rep 2017;11:46-57.

[2] Menon S, Rajeshkumar S, Kumar SV. A review on biogenic synthesis of gold nanoparticles, characterisation and its applications. Resource Efficient Technologies 2017;3(4):516-27.

[3] Rajeshkumar S, Naik P. Synthesis and biomedical applications of cerium oxide nanoparticles - a review. Biotechnol Rep 2018;17:1-5.

[4] Agarwal H, Menon S, Kumar SV, et al. Mechanistic study on antibacterial action of zinc oxide nanoparticles synthesized using green route. Chem Biol Interact 2018;286:60-70.

[5] Jain D, Daima HK, Kachhwaha S, et al. Synthesis of plant mediated silver nanoparticles of their antimicrobial activities. Dig J Nanometer Biostruck 2009;4:723-7.

[6] Parashar V, Parashar R, Sharma B, et al. Parthenium leaf extract mediated sysnthesis of silver nanoparticles: a novel approach towards weed utilisation. Dig J Nanometers Biostruck 2009;4(1):45-50.

[7] Rajeshkumar S. Green synthesis of different sized antimicrobial silver nanoparticles using different parts of plants - a review. Int J of Chem Tech Research 2016;9(4):197-208.

[8] Rajeshkumar S. Phytochemical constituents of fucoidan (Padina tetrastromatica) and its assisted AgNPs for enhanced antibacterial activity. IET Nanobiotechnol 2016;11(3):292-9.

[9] Sondi I, Solapek-Sondi B. Silver nanoparticles as antimicrobial agent: a case study on E. coli as a model for gram-negative bacteria. J Colloid Interface Sci 2004;275(1):177-82.

[10] Olalere OA, Abdurahman NH, Alara OR, et al. Parametric optimization of microwave reflux extraction of spice oleoresin from white pepper (Piper nigrum). Journal of Analytical Science and Technology 2017;8:8.

[11] Singh S, Kapoor IPS, Singh G, et al. Chemistry, antioxidant and antimicrobial potentials of white pepper (Piper nigrum L.) essential oil and oleoresins. Proc Natl Acad Sci Sect B 2013;83:357-66. 
[12] Roy A, Geetha RV, Lakshmi T. In Vitro evaluation of antibacterial activity of aqueous and ethanolic extracts of aesculus hippocastanum on oral microbes. Asian J Pharm Clin Res 2011;4(4):90-2.

[13] Geetha RV, Roy A. In vitro evaluation of the antibacterial activity of three herbal extracts on methicillin resistant Staphylococcus aureus (MRSA). J Pharm Sci Res 2013;5(10):207-9.

[14] Rajeshkumar S, Bharath LV. Mechanism of plantmediated synthesis of silver nanoparticles- a review on biomolecules involved, characterisation and antibacterial activity. Chem Biol Interact 2017;273:21927.

[15] Vanaja M, Gnanajobitha G, Paulkumar K, et al. Phytosynthesis of silver nanoparticles by Cissus quadrangularis - influence of physicochemical factors. Journal of Nanostructures in Chemistry 2013;3:17.

[16] Malarkodi C, Rajeshkumar S, Paulkumar K, et al. Bactericidal activity of bio mediated silver nanoparticles synthesized by Serratia nematodiphila. Drug Invention Today 2013;5(2):119-25.

[17] Gnanajobitha G, Paulkumar K, Vanaja M, et al. Fruit mediated synthesis of silver nanoparticles using vitis vinifera and evaluation of their antimicrobial efficacy. Journal of Nanostructures in Chemistry 2013;3:67.

[18] Rajeshkumar S. Synthesis of silver nanoparticles using fresh bark of Pongamia pinnata and characterization of its antibacterial activity against gram positive and gram negative pathogen. Resource-Efficient Technologies 2016;2(1):30-5.

[19] Kanagavalli U, Sadiq AM, Sathishkumar, et al. Plant assisted synthesis of silver nanoparticles using boerhaavia diffusa leaves extract and evolution of antibacterial activity. Research J Pharm and Tech 2016;9(8):1064-8.

[20] Asha S, Asha A, Rajeshkumar S. Evaluation of phytochemical constituents and antimicrobial activity of silver nanoparticle synthesized ipomoea nil against selected pathogens. Asian J Pharm Clin Res 2017;10(3):183-7.

[21] Asha S, Thirunavukkarasu P, Rajeshkumar S. Green synthesis of silver nanoparticles using mirabilis jalapa aqueous extract and their antibacterial activity against respective microorganisms. Res J Pharm Technol 2017;10(3):811-7.

[22] Kumar SV, Karpagambigai S, Rosy PJ, et al. Phyto-assisted synthesis of silver nanoparticles using solanum nigrum and antibacterial activity against salmonella typhi and Staphylococcus aureus. Mechanics, Materials Science \& Engineering 2017;9(1).

[23] Rajeshkumar S. Antioxidant activity of characterized silver nanoparticles synthesized using flower extracts of chrysanthemum indicum. Research Journal of Biotechnology 2017;12(8):38-43.

[24] Kumar SV, Rajeshkumar S. Plant-based synthesis of nanoparticles and their impact. In: Nanomaterials in plants, algae, and microorganisms. Academic Press 2018:33-57.

[25] Rajeshkumar S, Bharath LV. Controlling of food borne pathogens by nanoparticles. In: Bioorganic phase in natural food: an overview. Springer 2018:293-322.

[26] Rajeshkumar S. Antifungal impact of nanoparticles against different plant pathogenic fungi. In: Nanomaterials in plants, algae and microorganisms. Academic Press 2019:197-217.

[27] Menon S, Agarwal H, Kumar SV, et al. Biomemetic synthesis of selenium nanoparticles and its biomedical applications. In: Green synthesis, characterization and applications of nanoparticles. Elsevier 2019:165-97.

[28] Santhoshkumar J, Agarwal H, Menon S, et al. A biological synthesis of copper nanoparticles and its potential applications. In: Green synthesis, characterization and applications of nanoparticles. Elsevier 2019:199-221.

[29] Rajeshkumar S, Bharath LV, Geetha R. Broad spectrum antibacterial silver nanoparticle green synthesis: Characterization, and mechanism of action. In: Green synthesis, characterization and applications of nanoparticles. Elsevier 2019:429-444.

[30] RajeshKumar S, Lakshmi T, Naik P. Recent advances and biomedical applications of zinc oxide nanoparticles. In: Green synthesis, characterization and applications of nanoparticles. Elsevier 2019:445-57.

[31] Rajeshkumar S, Veena P, Santhiyaa RV. Synthesis and characterization of selenium nanoparticles using natural resources and its applications. In: Exploring the realms of nature for nanosynthesis. Springer 2018:63-79.

[32] Rajeshkumar S, Santhiyaa RV, Veena P. Plant and Its biomolecules on synthesis of silver nanoparticles for the antibacterial and antifungal activity. In: Exploring the realms of nature for nanosynthesis. Springer 2018:10945.

[33] Rajeshkumar S, Santhiyaa RV. Degradation dye using gold and silver nanoparticles synthesized by using green route and its characteristics. In: Exploring the realms of nature for nanosynthesis. Springer 2018:221-40.

[34] Sulaiman GM, Mohammed WH, Marzoog TR, et al. Green synthesis, antimicrobial and cytotoxic effects of silver nanoparticles using eucalyptus chapmaniana leaves extract. Asian Pac J Trop Biomed 2013;3(1):58-63.

[35] Manojkanna, Chandana CS, Gayathri R, et al. Synthesis and characterization of silver nano particles from plectranthus ambionicus extract and its antimicrobial activity against enterococcus faecalis and Candida albicans. J Pharm Sci Res 2017;9(12):2423-5. 